\title{
PREVENCIÓN DE LA DIFUSIÓN DE FAKE NEWS Y BULOS DURANTE LA PANDEMIA DE COVID-19 EN ESPAÑA. DE LA PENALIZACIÓN AL IMPULSO DE LA ALFABETIZACIÓN INFORMACIONAL
}

\section{PREVENTING THE SPREAD OF FAKE NEWS DURING THE COVID- 19 PANDEMIC IN SPAIN. FROM THE CRIMINALIZATION TO THE PROMOTION OF INFORMATION LITERACY}

\author{
(iD) 88 $\mathbb{R}^{\circ}$ Juan Antonio Martínez-Sánchez. Universidad de Cádiz. España \\ juanantonio.martinezsanchez@alum.uca.es
}

\section{Cómo citar el artículo:}

Martínez-Sánchez, J. A. (2022). Prevención de la difusión de fake news y bulos durante la pandemia de covid-19 en españa. De la penalización al impulso de la alfabetización informacional. Revista de Ciencias de la Comunicación e Información, 27, 15-32.https://doi.org/10.35742/rcci.2022.27.e236

\section{RESUMEN}

La difusión de fake news y bulos durante la pandemia de COVID-19 se ha convertido en una grave amenaza para la salud de los ciudadanos que, en momentos de crisis sanitaria como el actual, necesitan disponer de información veraz y fiable. Ello justifica la necesidad de adoptar determinadas medidas al objeto de prevenir y combatir la difusión de información falsa. En este contexto de desinformación, el gobierno español ha planteado la posibilidad de monitorizar y penalizar la difusión de fakes y bulos. Este artículo tiene como objetivo realizar un análisis crítico de la penalización como medida para combatir la difusión de fakes news y bulos durante la pandemia de COVID-19. Desde esta perspectiva, y como estrategia alternativa a la penalización se destaca la importancia de la alfabetización informacional como medio de formar consumidores de noticias críticos, bien informados y formados en el empleo de herramientas para verificar información y prevenir la propagación de noticias falsas. Penalizar la elaboración y difusión de noticias falsas es una medida polémica que entraña numerosos problemas desde un punto de vista ético, legal y, sobre todo, democrático. En la situación actual de crisis sanitaria resulta más eficaz concienciar a los ciudadanos sobre los riesgos que suponen las falsas noticias, enseñándoles a identificarlas y a evitar su difusión. Como estrategia para combatir la difusión de fakes y bulos, el fomento de la higiene informativa y la alfabetización informacional de la sociedad requieren de la participación y colaboración activa de los gobiernos, medios de comunicación y, sobre todo, de los ciudadanos.

PALABRAS CLAVE: COVID-19, fake news, bulo, penalización, verificación de información, alfabetización informacional, espíritu crítico

\section{ABSTRACT}

The spread of fake news and hoaxes during the COVID-19 pandemic has become a serious threat to the health of citizens who, in times of health crisis such as the 
current one, need to have truthful and reliable information. These circumstances justify the need to adopt certain measures in order to prevent and combat the dissemination of false information. In this context of disinformation, the Spanish government has raised the possibility of monitoring and penalizing the dissemination of fake news and hoaxes. This article aims to perform a critical analysis of the criminalization as a measure to combat the spread of fake news and hoaxes during the COVID-19 pandemic. From this perspective, and as an alternative strategy to penalization, it is highlighted the importance of information literacy is highlighted as a means of training critical news consumers, well informed and trained in the use of tools to verify information and prevent the spread of false news. Criminalizing the production of false news is a controversial measure that entails many problems from an ethical, legal and a democratic point of view. In the current context of health crisis, it is more effective to make citizens aware of the risks posed by false news, teaching them to identify them and avoid their dissemination. As a strategy to combat the spread of fakes and hoaxes, the promotion of information hygiene and information literacy in society requires the active participation and collaboration of governments, the media and citizens.

KEYWORDS: COVID-19; fake news; hoax; criminalization; fact checking; information literacy; critical spirit

\section{INTRODUCCIÓN}

Las fake news son noticias falsas difundidas deliberadamente con el objetivo de engañar, manipular, inducir a error, desprestigiar o enaltecer a una institución, grupo o persona, u obtener algún tipo de beneficio económico, ideológico o político (García, 2019).

Relacionado con el concepto de fake news y especialmente popularizado en nuestro país durante la pandemia provocada por el virus de la COVID-19 (SARS-CoV-2) se encuentra el término bulo (hoax, en inglés), que describe a "todo contenido intencionadamente falso y de apariencia verdadera, concebido con el fin de engañar a la ciudadanía, y difundido públicamente por cualquier plataforma o medio de comunicación social” (Salaverría et al., 2020, p. 4).

Entre las características que definen a las fakes se encuentran su falsedad e intencionalidad (Wardle, 2017; Bakir y McStay, 2018); su facilidad de propagación (Vosoughi, Roy y Aral, 2018); su persistencia en el tiempo, ya que continúan difundiéndose aun cuando hayan sido desmentidas; el hecho de contener una elevada carga emocional, que despierta sentimientos e influye en el estado de ánimo del lector, movilizándole a menudo a la acción (Álvarez Calvo, 2020); y su capacidad de multiplicarse en situaciones de incertidumbre y crisis, en los que el ser humano siente la necesidad imperiosa de buscar y obtener información (Masip et al., 2020).

Las fake news se han convertido en la actualidad en una grave amenazas para la democracia y la libertad de expresión (Bennett y Livingston, 2018), como así lo atestiguan los resultados del último eurobarómetro, según los cuales el $83 \%$ de los europeos perciben a las fakes como un problema para la democracia en general 
PREVENCIÓN DE LA DIFUSIÓN DE FAKE NEWS Y BULOS DURANTE LA PANDEMIA DE COVID-19 EN ESPAÑA. DE LA PENALIZACIÓN AL IMPULSO DE LA ALFABETIZACIÓN INFORMACIONAL

(European Commission, 2018). Las noticias falsas desinforman y polarizan a la opinión pública, afectando al buen funcionamiento democrático de la sociedad y alterando la convivencia del país (Allcott y Gentzkow, 2017; Bakir y McStay, 2018).

En situaciones de crisis e incertidumbre como la actual pandemia de COVID-19, a menudo las fake news generan alarma y confusión, poniendo en riesgo la vida de ciudadanos, que las toman por ciertas y llegan incluso a ignorar la información proveniente de fuentes contrastadas y/o oficiales. En este sentido la difusión de fakes constituye también una grave amenaza para los canales oficiales de comunicación, especialmente los de las administraciones públicas (Bennett y Livingston, 2018).

\section{OBJETIVOS}

Partiendo de esta situación y considerando las múltiples consecuencias y efectos adversos de las noticias falsas, en el presente trabajo se pretende exponer distintas estrategias y medidas para prevenir y combatir la elaboración y difusión de fake news y bulos. Con este objetivo se realiza un análisis crítico de la penalización como posible estrategia impulsada por el Gobierno español para combatir la elaboración y difusión incontrolada de fakes y bulos sobre el coronavirus y la pandemia de COVID-19 en nuestro país.

En contraposición a la estrategia de la penalización, resaltamos el papel de la alfabetización informacional como medio de fomentar el pensamiento crítico de la población para dotarla de un instrumento eficaz para verificar la información que consume. Desde esta perspectiva y como posible solución al problema de la difusión de información falsa, presentamos una serie de medidas y pasos que faciliten al ciudadano identificar la información falsa que circula por las plataformas digitales y redes sociales, para poder prevenir y combatir así su difusión.

\section{FAKES Y COVID-19}

En los últimos años hemos asistido a una notable proliferación de bulos y noticias falsas relacionadas con la salud, el bienestar y las enfermedades (Elsevier Connect, 2020). De este modo, la actual pandemia provocada por el virus SARS-CoV-2 se ha convertido en un auténtico caldo de cultivo para la proliferación de fakes y bulos, debido a varios factores.

En primer lugar destacamos la necesidad humana de estar informado en situaciones de crisis e incertidumbre, en la que priman los aspectos emocionales sobre los racionales. Desde esta perspectiva, la gran incertidumbre y la fuerte carga emocional relacionada con la crisis sanitaria, económica y social que acompaña a la pandemia de COVID-19, produce una necesidad acentuada de información como estrategia para adaptarse y comportarse adecuadamente ante una situación insólita e inesperada (Montesi, 2020).

Otro factor a considerar es la ausencia de información oficial fiable sobre la enfermedad y la actitud irresponsable de algunas autoridades y políticos, que han actuado a menudo como meros propagadores de desinformación (Pérez-Dasilva, Meso-Ayerdi y Mendiguren-Galdospín, 2020). Poco ha contribuido a mejorar la 
situación el papel desempeñado por los medios de comunicación, a los que buena parte de la ciudadanía percibe actualmente como sensacionalistas y condicionados por su línea editorial a la hora de informar sobre la pandemia, generando con ello la alarma social y la pérdida de confianza de los ciudadanos (Masip et al., 2020).

Finalmente, señalamos que, durante el confinamiento decretado por la mayoría de países para intentar contener la propagación del virus de la COVID-19, las redes sociales se han convertido en una fuente esencial para informarse y, por tanto, para desinformarse (Ortega, 2020). Perdida la confianza en políticos, medios informativos y autoridades a la hora de obtener información fiable sobre el virus y la enfermedad que provoca, buena parte de la ciudadanía ha recurrido a las redes sociales en busca de esa información que le permita comprender y adaptarse a la nueva situación.

En este contexto de desinformación conformado por las anteriores circunstancias hoy día asistimos a lo que se denomina "infodemia" (infodemic), definida como un exceso de información -alguna exacta y otra no- que dificulta que las personas encuentren fuentes veraces y fiables cuando las necesitan (Organización Mundial de la Salud, 2020).

Tal ha sido la proliferación de noticias falsas durante la pandemia de COVID-19 en nuestro país que el Ministerio del Interior editó con fecha 17 de marzo de 2020 un informe en el que se recogían más de 50 bulos y fakes sobre el tema (Centro de Inteligencia contra el Terrorismo y el Crimen Organizado, CITCO, 2020). En la misma línea, tanto a nivel nacional como internacional, numerosas organizaciones y medios de verificación de información (Fact-checks) han elaborado extensos y detallados listados de fakes y bulos difundidos desde que se inició la epidemia en China. ${ }^{1}$

La mayoría de estas fakes y bulos persiguen generar alarma y confusión entre la población. Ello se ha reflejado en noticias que han difundido información falsa sobre el contagio y fallecimiento por COVID-19 de personalidades y autoridades, como el papa Francisco, la Familia Real casi al completo y varios miembros del Gobierno, incluidos el presidente Pedro Sánchez o el expresidente Pablo Iglesias.

Es importante destacar que un nutrido grupo de bulos difundidos se refieren a la gestión sanitaria de la pandemia, y aspectos clínicos y médicos como el contagio, la prevención o tratamiento de la enfermedad (Maldito Bulo, 2021). La confusión que inducen estas fakes y bulos aumenta ante la ausencia de información oficial veraz y contrastada, y en la medida que algunas de ellas provienen de supuestos profesionales o expertos en la materia que difunden sus mensajes a través de las redes sociales (Peña, Bermejo y Zanni, 2021).

Particularmente difundidos han sido los bulos sobre modos de contagio y supuestas medidas para prevenir el contagio y tratar la enfermedad (Sánchez-Duarte y Magallón, 2020; Moreno-Castro, Vengut-Climent, Cano-Orón y Mendoza-Poudereux, 2021). En cuanto a los modos de contagio citamos "el coronavirus no se transmite

\footnotetext{
1 Valga como ejemplo de ello que, a fecha 16 de julio de 2021, el verificador de hechos Maldita.es había identificado más de 1100 noticias falsas, mentiras y bulos sobre la COVID-19 (Maldito Bulo, 2021).
} 
PREVENCIÓN DE LA DIFUSIÓN DE FAKE NEWS Y BULOS DURANTE LA PANDEMIA DE COVID-19 EN ESPAÑA. DE LA PENALIZACIÓN AL IMPULSO DE LA ALFABETIZACIÓN INFORMACIONAL

por el aire", "los pacientes asintomáticos no contagian", "barba y bigote aumentan el contagio", "Fernando Simón ha dicho que lo mejor es infectarse ahora porque luego no habrá cama para todos", o que la Organización Mundial de la Salud (OMS) "ha pedido evitar tener sexo sin protección con animales para evitar el contagio" (Maldito Bulo, 2021).

Por otro lado, y basándose en el hecho de que la dificultad respiratoria es uno de los síntomas graves del coronavirus, un bulo avisaba que "podemos saber si estamos contagiados de coronavirus si logramos contener la respiración durante más de diez segundos". Otro bulo que se extendió y generalizó prácticamente por todas las comunidades es que aviones o helicópteros iban a fumigar centros urbanos para prevenir el contagio.

Además de las anteriores, otras supuestas medidas difundidas para prevenir el contagio por coronavirus han sido practicar sexo al menos cada dos días, fumar, consumir cocaína, untarse la piel con aceite de sésamo, ingerir grandes cantidades de agua o enjuagarse la garganta con agua caliente y sal o vinagre, desinfectarse con toallitas húmedas para bebés o lavarse las manos con orina infantil. Según otros bulos, la ingesta de productos como vino, café, vitamina C o ácidos grasos omega también prevendrían el contagio.

En cuanto a la mascarilla como medida de prevención del contagio, se han publicado varias informaciones falsas sobre su ineficacia y posibles efectos adversos de su uso, incluyendo la hipoxia, enfermedades neurodegenerativas o el aumento del riesgo de padecer cáncer (Lorenzo, 2020)

También han sido numerosos los bulos sobre el tratamiento de la enfermedad con supuestas curas y remedios como beber agua caliente, tomar clorito de sodio, limón y bicarbonato, comer plátanos o exponerse a la luz de lámparas ultravioleta. En esta línea, la información que aseguraba que el ibuprofeno agravaba las infecciones por COVID-19 provocó tal polémica y confusión que el Ministerio de Sanidad tuvo que desmentirlo oficialmente (Agencia Española de Medicamentos y Productos Sanitarios, 2020).

Por último, podemos citar a aquellos bulos que se basan en creencias y teorías irracionales y conspiranoicas, por ejemplo sobre el origen del virus. Según algunos de estos bulos el coronavirus habría sido creado intencionadamente como arma biológica para reducir la población mundial, principalmente la de ancianos, y activado por la tecnología 5G. La elaboración de la vacuna ha sido igualmente objeto de múltiples bulos por partidarios de teorías conspiranoicas y antivacunas, incluyendo la supuesta muerte de voluntarios de ensayos clínicos, que la vacuna provoca infertilidad o "se fabrica a base de células de fetos abortados" (Furlan, 2021).

Desde las teorias conspiranoicas se ha llegado incluso a negar la existencia del virus y la pandemia y a rechazar medidas preventivas como el uso de mascarilla, el distanciamiento social y la administración de la vacuna. En consecuencia, los numerosos perjuicios y efectos negativos que generan fakes y bulos, tanto en la 
convivencia democrática de la sociedad como en la salud física y psicológica de sus ciudadanos, llevan a la necesidad de identificarlas, combatirlas y neutralizarlas.

Entre las medidas propuestas para luchar contra la difusión de fakes y bulos en internet y redes sociales podemos citar: a) impulsar un periodismo veraz y de calidad al alcance de todos; b) modificar los algoritmos de los motores de búsqueda de internet; c) potenciar los verificadores de información y hechos; d) monitorizar y bloquear determinados portales web, perfiles y cuentas en redes sociales; e) penalizar la difusión de falsas noticias constitutivas de delitos; y f) informar y formar a los ciudadanos para que aprendan a distinguir entre la información veraz y la falsa.

\section{LA VÍA DE LA PENALIZACIÓN}

En la gestión de la crisis de la COVID-19 el Gobierno español parece haber optado por la vía de la monitorización y control de las redes sociales para detectar y denunciar noticias falsas, así como por el impulso de su posible penalización, medidas ambas que han suscitado una gran polémica. Desde esta perspectiva se ha defendido la necesidad de establecer mayores y más severos mecanismos de control contra las fake news, e incluso una nueva legislación para luchar contra la desinformación (Maldonado, 2020).

Así, el día 6 de abril de 2020, durante una rueda de prensa celebrada en el Palacio de La Moncloa el ministro de Interior Fernando Grande-Marlaska señaló que "estamos monitorizando las redes sociales y todos aquellos bulos y noticias falsas que puedan tener un contenido criminal, y lo ponemos en conocimiento de la fiscalía o la autoridad judicial" (Pool Moncloa / Villar y del Monte, 2020).

Pocos días después y a instancias del Gobierno, la fiscal general del Estado Dolores Delgado ordenó a la Fiscalía General elaborar un informe acerca del impacto de las falsas noticias en la opinión pública y su posible encaje como delitos nuevos o asociados a otros ya existentes en el Código Penal actual. Esta medida obedecía a un intento del Gobierno de acabar con las noticias falsas propagadas por VOX y a que "algunos expertos" consideraban que los responsables del aparato de propaganda de dicho partido podrían estar incurriendo en una especie de "nuevo delito de terrorismo informativo, sabotaje o creación de alarma social" (Antequera, 2020).

Según el consiguiente estudio realizado por la Secretaría Técnica de la Fiscalía General del Estado, en función de su forma, difusión y trascendencia, las noticias falsas y bulos difundidos durante la crisis del coronavirus podrían incurrir hasta en una decena de tipos penales, incluido los de odio, descubrimiento y revelación de secretos, delito contra la integridad moral, desórdenes públicos, injurias y calumnias, delitos contra la salud pública (Garea, 2020).

Pero la polémica saltó a los medios de comunicación el día 19 de abril de 2020, cuando el entonces jefe de Estado Mayor de la Guardia Civil, general José Manuel Santiago, declaró durante la rueda de prensa del comité de seguimiento de la crisis del coronavirus que el instituto armado trabajaba en la lucha contra los bulos 
PREVENCIÓN DE LA DIFUSIÓN DE FAKE NEWS Y BULOS DURANTE LA PANDEMIA DE COVID-19 EN ESPAÑA. DE LA PENALIZACIÓN AL IMPULSO DE LA ALFABETIZACIÓN INFORMACIONAL

difundidos por redes sociales, con el objetivo de minimizar "el clima contrario" al Gobierno por su gestión contra la crisis (Terradillos, 2020).

A raíz de la controversia suscitada por las declaraciones del general Santiago, el 21 de abril la entonces ministra de Educación y Formación Profesional María Isabel Celaá declaró que el Gobierno debía "proteger a la ciudadanía de mensajes falsos" y que no podía aceptar "mensajes negativos, mensajes falsos en definitiva" que fueran en contra de los criterios científicos y "la integridad de las instituciones públicas" (Radiotelevisión Española, 2020).

Sin embargo, la posible penalización de las fakes y bulos plantea numerosos problemas relacionados con aspectos conceptuales, jurídicos y éticos.

En primer lugar, la ausencia de una definición precisa y consensuada de fake news (Tandoc, Lim y Ling, 2018), que se relaciona con la necesidad de distinguir entre la difusión intencional de información falsa a sabiendas de que lo es (disinformation) y la difusión de información falsa o errónea de manera involuntaria o inconsciente, por desconocimiento, ignorancia o por un simple afán de ganar popularidad (misinformation) (Wardle, 2017; Bakir y McStay, 2018). La falta de una definición precisa de fake news dificulta a menudo poder identificarlas con certeza e impide a los gobiernos legislar contra la desinformación (Encabo, 2020).

Relacionado con lo anterior, se ha señalado la falta de neutralidad de los verificadores de hechos encargados de decidir en nuestro país qué es y qué no es una fake, fundamentalmente Maldita.es y Newtral, debido a su falta de imparcialidad y neutralidad ideológica (Encabo, 2020; González, 2019; Pérez Rodríguez, 2020).

Por otra parte, desde un punto de vista jurídico, la difusión de noticias falsas parece tener a priori un complicado encaje en el Código Penal actual, ya que como reconoció finalmente la propia fiscal general del Estado, Dolores Delgado, la elaboración y / o difusión de fakes y bulos no es en sí mismo un delito (Urreiztieta, 2020). Solo cabría penalizar la difusión de fakes y bulos si son utilizados como medio para cometer ciertos delitos, como los de injurias y calumnias o el de fomentar el odio, hostilidad, discriminación o violencia hacia determinados colectivos por razón de la pertenencia de sus miembros a una etnia, raza o nación (artículo 510 $\mathrm{CP})$.

Prohibir la difusión de noticias falsas también podría suponer un ataque a los derechos fundamentales recogidos en la Constitución española, ya que supondría limitar el derecho a la libertad de expresión y a una información veraz (Mejías y López, 2020), otorgando al Gobierno la facultad de controlar la información que recibe la sociedad en base a sus propios intereses ideológicos (Encabo, 2020).

Finalmente, y desde un punto de vista ético y moral, difícilmente estaría legitimado el Gobierno para impulsar la penalización de las fakes y bulos cuando el propio presidente Pedro Sánchez ha sido señalado en varias ocasiones por haber difundido durante la pandemia noticias e información calificada como falsa por varios medios de comunicación y por los verificadores de hechos Maldita.es y Newtral (Maldito Dato, 2020; Larraz, 2020; Trillo, 2020; McLean y Pérez Maestro, 2020; CNN, 2020). 


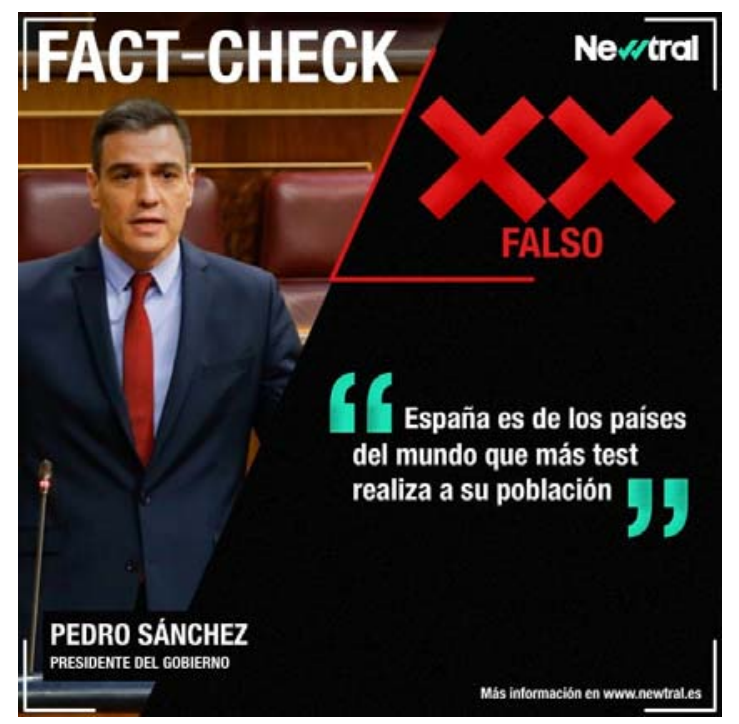

Figura 1: Difusión de información falsa por fuentes oficiales.

Fuente: https://www.newtral.es/sanchez-espana-es-de-los-paises-del-mundo-quemas-test-realiza-a-su-poblacion/20200425/

\section{CNN॰ @CNN.9 may.}

Spanish Prime Minister Pedro Sánchez said rankings by Johns Hopkins University showed Spain was fifth in the world in testing rates. But those international rankings appear not to exist.

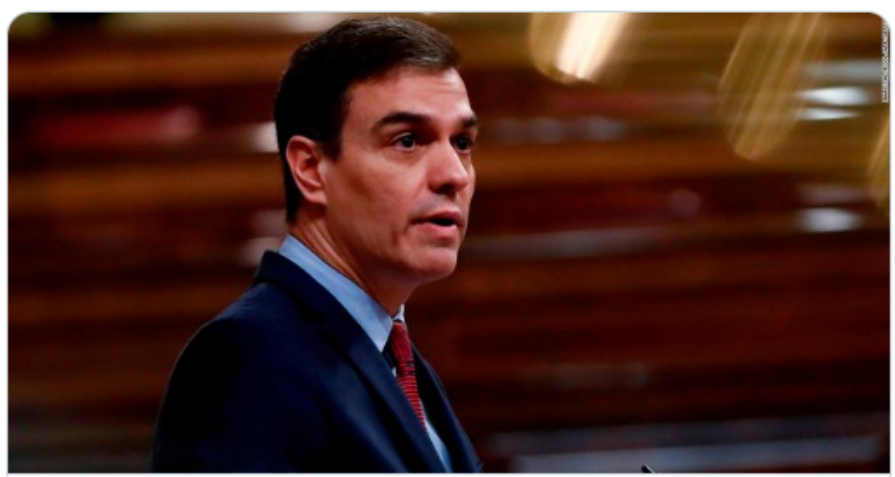

Spanish prime minister fails to prove existence of international coronavi... Spanish Prime Minister Pedro Sánchez said rankings by Johns Hopkins University showed Spain was fifth in the world in testing rates. But those... of cnn.com
Q 3 mil
โ】 $27,2 \mathrm{mil}$
- $33,4 \mathrm{mil}$ 个

Figura 2: Difusión de información falsa por fuentes oficiales.

Fuente: https://twitter.com/cnn/status/1259336128634720256 
PREVENCIÓN DE LA DIFUSIÓN DE FAKE NEWS Y BULOS DURANTE LA PANDEMIA DE COVID-19 EN ESPAÑA. DE LA PENALIZACIÓN AL IMPULSO DE LA ALFABETIZACIÓN INFORMACIONAL

\section{FAKES Y COVID-19 CONTRA LAS FAKES, ALFABETIZACIÓN INFORMACIONAL Y ESPÍRITU CRÍTICO}

Independientemente de la monitorización y penalización de la difusión de determinadas noticias falsas y bulos que pudieran contener contenido o intención criminal, su prevención y control pasa por concienciar a la ciudadanía sobre la importancia de evitar ser víctimas de la manipulación y de no participar en estas cadenas de desinformación (Encabo, 2020).

Bien sea por falta de pensamiento crítico o por una actitud infantil e ingenua, muchas personas se convierten en "colaboradoras necesarias" en la propagación de mensajes malintencionados que provocan odio, miedo, confusión e insolidaridad. En este sentido, los ciudadanos deben ser conscientes de que no deben compartir aquella información cuya veracidad no esté contrastada, y que deben exigir siempre noticias comprobadas y auténticas, ya que sólo la información veraz garantiza su libertad (Álvarez Calvo, 2020).

La medida más efectiva para identificar y combatir las falsas noticias es formar consumidores de noticias críticos, bien formados e informados (Parra-Valero y Oliveira, 2018). Ello se consigue fundamentalmente a través de la denominada alfabetización informacional (Information Literacy), definida como "la habilidad de pensar críticamente y emitir juicios equilibrados sobre cualquier información que encontremos y utilicemos" (Chartered Institute of Library and Information Professionals, CILIP, 2018, p. 3).

La alfabetización informacional tiene como principales objetivos fomentar el pensamiento crítico entre los lectores y alentarles a que consuman información procedente de diversas fuentes para que sean capaces de distinguir fuentes de información fiables de las que no lo son (Finley, McGowan y Kluever, 2017), así como luchar contra los propios sesgos ideológicos (Aparici, García-Marín y RincónManzano, 2019). Por tanto, el pensamiento crítico se constituye en una habilidad esencial y necesaria para detectar y combatir las falsas noticias (International Federation of Libraries Association, IFLA, 2021; Montesi, 2020).

\subsection{Espíritu crítico y verificación de información}

Ejercer el pensamiento crítico para contrastar la veracidad o falsedad de una información implica poner en marcha un proceso verificador compuesto de varios pasos (Gragnani, 2018; IFLA, 2021; Llorca, 2017; Newtral, 2019). Estos pasos son de gran utilidad para identificar y combatir la difusión de fakes y bulos durante la pandemia de COVID-19.

1. Ante la menor duda sobre la veracidad de una noticia, la primera regla es no compartirla sin haberla contrastado previamente (Gragnani, 2018). Los bulos y las noticias falsas buscan manipular nuestras emociones, crear indignación, alarma o influir en nuestro estado de ánimo para que las compartamos en redes sociales sin pensar (Newtral, 2019). Por tanto es esencial contrastar y verificar las noticias antes de darle crédito y difundirlas, lo que exige un ejercicio de prudencia, reflexión y de control de 
impulsos para no caer en la trampa del retuit automático (IFeel, 2020).

2. A la hora valorar la veracidad o falsedad de una noticia debemos ser conscientes de la posibilidad de ser víctimas de determinados sesgos cognitivos, que afectan tanto a la búsqueda de información que realizamos, como a la selección, procesamiento y análisis que hacemos de ella. Los sesgos cognitivos son interpretaciones erróneas de la información que afectan a nuestra capacidad de percibir el mundo que nos rodea, elaborar nuestros pensamientos y juicios, tomar decisiones y actuar en consecuencia.

Nuestros intereses y creencias personales, culturales, religiosas, políticas e ideológicas pueden condicionar la forma en que nos comportamos ante las noticias falsas, llevándonos a aceptar como verdaderas aquellas fakes y bulos que contienen información afín a nuestros intereses y creencias. Este proceso constituye la esencia del denominado sesgo de confirmación ${ }^{2}$, que nos lleva a dar mayor veracidad a aquellas noticias e información que encaja con nuestras ideas y prejuicios, aunque sean falsas (Aparici, García-Marín y Rincón-Manzano, 2019).

3. Desconfiar de los titulares. A menudo las fakes se comparten sólo porque el titular despierta la atención del lector y moviliza sus emociones, como el miedo o la indignación (Bakir y McStay, 2018). A este respecto, los titulares 0 encabezados de las noticias pueden proporcionarnos información útil sobre su veracidad o falsedad.

Puede ocurrir que, aunque el titular contenga enunciados o afirmaciones falsas, exageradas o sensacionalistas, el cuerpo o contenido de la noticia exprese lo contrario, matice o incluso contradiga lo apuntado por el titular. Por ello es importante no quedarse en el titular sino leer la noticia entera (Gragnani, 2018).

Otra forma de confirmar la veracidad de la noticia es rastrear el titular en buscadores de internet. Si es verdadera, es probable que otros medios de comunicación la hayan reproducido ya; por el contrario, si es falsa puede que algunos verificadores de hechos hayan comprobado que se trata de un bulo o rumor falso (Gragnani, 2018; Newtral, 2019).

4. Es importante igualmente comprobar que la noticia no sea una broma. Existen determinados periódicos y portales satíricos que, en clave de humor, difunden noticias e información ficticia / falsa tanto a través de sus plataformas digitales y webs como en redes sociales, de manera que a veces puede resultar difícil diferenciar las noticias falsas del humor o la sátira. ${ }^{3}$

\footnotetext{
2 En Psicología Cognitiva se define el sesgo de confirmación como la tendencia a buscar, favorecer, interpretar y recordar la información que confirma las propias creencias, ideas o hipótesis; y a ignorar o minusvalorar la información disconfirmatoria (Plous, 1993).

${ }^{3}$ En España podemos citar los casos de El Mundo Today (www.elmundotoday.com) y Hay Noticias (www.haynoticias.es). En septiembre de 2010 los informativos de la cadena de TV Cuatro daba como cierta y reproducían una noticia publicada por El Mundo Today con el titular "Los nuevos modelos de iPod no tendrán música de mierda". En otra ocasión fue el diario 20 Minutos, quien se hizo eco de una fake de este medio según la cual un cliente del restaurante El Bulli se había comido la factura "creyendo que era otro plato" (Bravo, 2010).
} 
Del mismo modo, hay que tener en cuenta que ciertas campañas publicitarias (publirreportajes, contenidos patrocinados) hacen uso de noticias falsas para captar posibles clientes. Por la misma razón debemos cuestionar la información difundida por blogueros, youtubers e influencers en redes sociales, ya que frecuentemente están patrocinados económicamente por determinadas marcas y persiguen intereses comerciales (Llorca, 2017).

5. Debemos desconfiar igualmente de la información que se difunde aparentemente como "noticias exclusivas" o "noticias bomba". En el mundo tecnológico y globalizado en que vivimos es muy difícil que un particular se anticipe a un medio de comunicación a la hora de comunicar una exclusiva verdadera. Por ello hemos de ser prudentes ante supuestas noticias exclusivas procedentes de fuentes desconocidas y que nos llegan a través de las redes sociales.

6. Otra medida necesaria es verificar la procedencia o autoría de la noticia y la fiabilidad de sus fuentes, asegurándonos de que estas sean conocidas y/o de confianza. A menudo fakes y bulos provienen de páginas o portales web que tratan de hacerse pasar por medios de comunicación fiables, utilizando URL's (Uniform Resource Locator) muy parecidas a las de éstos. Una URL falsa, que trate de imitar a una real o que corresponda a un dominio inexistente es indicio de que nos encontramos ante una noticia falsa (Álvarez Calvo, 2020).

Realizar una búsqueda en internet, introduciendo el nombre del medio o del autor de la noticia nos permitirá conocer el perfil profesional del autor. Igualmente, deberemos prestar atención a posibles sesgos políticos e ideológicos del autor y del medio que publica la noticia (Gragnani, 2018). Para ello podemos visualizar otras noticias insertadas en la página web donde se incluye la información a verificar y analizar si son igual de llamativas o sorprendentes; o comprobar si la página dispone de algún apartado tipo "Quiénes somos" o "Sobre nosotros", en el que podamos obtener información sobre el medio (Newtral, 2019).

Especialmente cuidadosos deberemos ser con las noticias que recibimos en redes sociales, correo electrónico o aplicaciones de mensajería instantánea ya que, aunque suelen provenir de contactos y conocidos, suelen hacer referencia a otros supuestos parientes o allegados, de modo que la fuente real es anónima o no identificable. Podemos preguntar a quién nos remitió la noticia de quién la ha recibido a su vez, si confía en esa persona y si ha verificado de alguna manera su contenido (Gragnani, 2018).

En el caso de Hay Noticias, famosa fue su noticia según la cual dos monaguillos gallegos habían sido detenidos por introducir marihuana en el botafumeiro, una noticia vista por más de dos millones de personas y que recibió más de 250.000 interacciones en redes sociales. O su "invent" sobre la mujer que llevaba 28 años haciéndose pasar por ciega para no saludar a la gente, que fue publicada en 23 países y traducida a 13 idiomas, siendo recogida por medios serios como Marca, Catalunya Press, Cadena Dial o Diario de Navarra (Gosálvez, 2018). 
También debemos desconfiar de perfiles o cuentas anónimas en Facebook o Twitter, ya que suelen poseer algún tipo de motivación oculta, generalmente política o ideológica, o tratarse de robots (bots) al servicio de alguna causa.

7. La forma en la que la noticia está escrita, su estructura o formato y el lenguaje utilizado pueden proporcionarnos algunas pistas sobre su veracidad. Es habitual que las fakes incluyan adjetivos innecesarios y/o abusen del lenguaje coloquial y del uso de pronombres personales, opiniones y primeras personas del singular (Llorca, 2017). Del mismo modo, la presencia de expresiones inadecuadas, faltas de ortografía o rasgos impropios de la redacción periodística constituye otra señal de alerta (Álvarez Calvo, 2020).

8. Cuando una noticia es cierta, es más probable que cite fuentes, incluya enlaces a otro contenido o fuentes externas o mencione documentos oficiales (Gragnani, 2018). Por el contrario, las noticias falsas suelen presentar el contenido sin citar ningún enlace, persona, estadística o fuente oficial que las avale (Newtral, 2019). Por tanto, debemos desconfiar de la veracidad de las noticias que mencionan a estudios, informes $u$ opiniones de expertos sin incluir el enlace a dichas fuentes. Si la noticia incluye dichos enlaces, acudiremos a las fuentes originales para confirmar la información (Llorca, 2017).

9. Otro requisito necesario es verificar el contexto de la noticia, comprobando si está fechada. Sacar una noticia de su contexto original y divulgarla en una fecha diferente constituye otro ejemplo claro de desinformación a tener en cuenta (Gragnani, 2018).

Las imágenes, fotografías e infografías que acompañan a la noticia o información también pueden ser reveladoras de su veracidad o falsedad. Estas imágenes pueden haber sido manipuladas o retocadas mediante programas informáticos; o ser auténticas pero sacadas o fuera de contexto para hacer creer las mentiras a las que acompañan.

Determinar la falsedad de las imágenes exige el manejo de software especializado, así como cierta capacitación técnica que no siempre está al alcance de cualquier usuario (Aparici, García-Marín y Rincón-Manzano, 2019), lo que requiere el impulso y desarrollo de mecanismos de verificación de imágenes (Cea-Esteruelas, 2018). Ante la sospecha de que una imagen haya sido sacada de su contexto original es recomendable realizar una "búsqueda inversa" (Gragnani, 2018), para obtener toda la información disponible sobre esa imagen. ${ }^{4}$

Las fakes y bulos pueden adoptar también la forma de grabaciones de audio o vídeo realizadas por personas aparentemente sin malas intenciones ni motivaciones políticas o ideológicas. Estas grabaciones suelen tratar de crear alarma y confusión difundiendo algún tipo de peligro próximo o inminente,

\footnotetext{
${ }^{4}$ La "búsqueda inversa" es una técnica que permite obtener información sobre una imagen, localizar su fuente y cuando fue tomada o editada, identificar las páginas web donde aparece o incluso encontrar a la persona que la creó. Existen aplicaciones informáticas para realizar este tipo de búsquedas, por ejemplo: https://images.google.com/, https://reverse.photos/ o https://yandex.com/images/
} 
PREVENCIÓN DE LA DIFUSIÓN DE FAKE NEWS Y BULOS DURANTE LA PANDEMIA DE COVID-19 EN ESPAÑA. DE LA PENALIZACIÓN AL IMPULSO DE LA ALFABETIZACIÓN INFORMACIONAL

convencernos de algo sin pruebas o incitar al odio contra algún grupo o colectivo concreto (Newtral, 2019). Una búsqueda en internet introduciendo en un buscador las palabras claves que resumen la noticia y el nombre de la red social en que ha sido difundida puede ayudar a contrastar su veracidad (Gragnani, 2018).

10.Por último, debemos tener en cuenta que la propia tecnología nos ofrece varias herramientas para realizar automáticamente algunos de los pasos anteriores. Es el caso de BS Detector y de Fake News Detector, aplicaciones de software (plug-in) para navegadores de internet que analizan el contenido de las páginas webs que visitamos y permiten detectar la existencia de noticias falsas. Del mismo modo podemos acudir a verificadores de información $y$ hechos como FactCheck.org o PolitiFact.com en Estados Unidos; o Maldita.es y Newtral en España.

\section{CONCLUSIONES}

La elaboración y difusión de fakes y bulos es un proceso comunicativo que adquiere gran importancia en situaciones de crisis e incertidumbre. Fakes y bulos suponen una amenaza para la democracia de los países y para la convivencia y salud de sus ciudadanos. Además, en tiempos de crisis sanitaria como la actual pandemia de COVID-19, la difusión intencional de información falsa crea confusión y alarma, contagia el miedo y contribuye a la politización y polarización de la sociedad.

Es en momentos de incertidumbre y crisis como el actual cuando la ciudadanía necesita información actualizada, inmediata y, sobre todo veraz y precisa. Ello requiere la adopción de diversas medidas para combatir la elaboración y difusión de noticias falsas, entre ellas impulsar un periodismo de calidad; potenciar los mecanismos de verificación de información (fact-checking); monitorizar y, si es preciso, bloquear determinados portales web, perfiles y cuentas en redes sociales; y penalizar ciertas conductas que puedan ser constitutivas de ilícitos penales.

En el contexto de la pandemia de COVID-19 y de la crisis sanitaria e informativa que le acompaña, el Gobierno español ha planteado la posibilidad de penalizar la elaboración y difusión de fakes y bulos, bien mediante de la creación de nuevos tipos penales que incluyan el denominado terrorismo informativo, bien mediante la inclusión de estas conductas en tipos penales actualmente recogidos en el Código Penal, como es el caso de los delitos de incitación al odio, injurias o calumnias. Sin embargo, la posible penalización de fakes y bulos entraña numerosos problemas difíciles de resolver y que incluyen cuestiones formales, éticas, morales y legales.

En todo caso, prevenir y combatir la desinformación durante la actual pandemia de pasa por impulsar la alfabetización informacional y la higiene informativa de la sociedad, para que los ciudadanos sean conscientes de los riesgos que suponen las fakes y bulos, y aprendan a usar estrategias y herramientas para identificarlos y prevenir su propagación incontrolada.

La alfabetización informacional implica fomentar un mayor conocimiento entre la población de las fake news y bulos, sus características, sus mecanismos de 
producción y difusión y sobre todo sus consecuencias para la sociedad. En este sentido, y como han señalado diversos autores (Costa-Sánchez y López-García, 2020; Salaverría et al., 2020) resaltamos la necesidad de impulsar la investigación sobre el tema y de transferir y transmitir los resultados de dicha investigación a la población.

Como estrategia, la alfabetización informacional requiere un papel activo de los medios de comunicación, que deben convertirse en referentes informativos de calidad para la ciudadanía, abandonando los sesgos ideológicos que caracterizan en buena medida a sus líneas editoriales en aras de una mayor objetividad y neutralidad política.

La alfabetización informacional persigue enseñar a los ciudadanos a actuar de manera reflexiva, crítica y responsable, para que contrasten la veracidad de la información que reciben antes de compartirla o difundirla. Ello posibilitará la implantación de mecanismos y canales informativos y comunicativos que faciliten la verificación de noticias mediante la creación, por ejemplo, de listas y comunidades virtuales de usuarios y lectores en redes sociales. De esta manera, y en un ejercicio de responsabilidad compartida, los ciudadanos podrán contrastar la veracidad de la información que recibe y, en caso de que ésta no sea verdadera, alertar de su falsedad a quien se la envió (Editorial Nobbot, 2020).

Por tanto, la alfabetización informacional se erige en una de las principales herramientas para luchar contra la desinformación que causas fakes news y bulos. No olvidemos que no hay mayor enemigo para la desinformación que una ciudadanía bien formada e informada.

\section{REFERENCIAS}

Agencia Española de Medicamentos y Productos Sanitarios. (2020). La AEMPS informa que ningún dato indica que el ibuprofeno agrave las infecciones por COVID-19. Ministerio de Sanidad. https://tinyurl.com/ummr4b6

Allcott, H. y Gentzkow, M. (2017). Social Media and Fake News in the 2016 Election. Journal of Economic Perspectives, 31(2), 211-236. https://doi.org/10.1257/jep.31.2.211

Álvarez Calvo, P. (2020). 'Fake news', la otra pandemia que arrasa el planeta. Cinco Días. https://tinyurl.com/dztud37r

Antequera, J. (2020). Los «tuiteros» de Vox se enfrentarán a una pena de hasta 5 años de cárcel por sus bulos en redes sociales. Diario 16. https://tinyurl.com/3r3c8874

Aparici, R., García-Marín, D. y Rincón-Manzano, L. (2019). Noticias falsas, bulos y trending topics. Anatomía y estrategias de la desinformación en el conflicto 
PREVENCIÓN DE LA DIFUSIÓN DE FAKE NEWS Y BULOS DURANTE LA PANDEMIA DE COVID-19 EN ESPAÑA. DE LA PENALIZACIÓN AL IMPULSO DE LA ALFABETIZACIÓN INFORMACIONAL

catalán. El Profesional de la Información, 28(3), https://doi.org/10.3145/epi.2019.may.13

Bakir, V. y McStay, A. (2018). Fake News and the Economy of Emotions: Problems, causes, Solutions. Digital Journalism, 6(2), 154175. https://doi.org/10.1080/21670811.2017.1345645

Bennett, W. L. y Livingston, S. (2018). The disinformation order: Disruptive communication and the decline of democratic institutions. European Journal of Communication, 33(2), 122-139. https://doi.org/10.1177/0267323118760317

Bravo, G. (2010). Un periódico satírico online deja en evidencia a la 'prensa seria'. El Confidencial. https://tinyurl.com/ydccr2w7

Cea-Esteruelas, N. (2018). La fotografía periodística y los social media: la jornada del 1 de octubre en Cataluña. Miguel Hernández Communication Journal, 2(9), 359-377. https://doi.org/10.21134/mhcj.v0i9.260

Centro de Inteligencia contra el Terrorismo y el Crimen Organizado, CITCO. (2020). Fake news y desinformaciones sobre el virus COVID-19 en fuentes abiertas. Madrid: Ministerio del Interior. https://tinyurl.com/t8kdwfxx

Chartered Institute of Library and Information Professionals. (2018). Definition of information literacy. Cilip. The Library and Information Association; Information Literacy Group. https://infolit.org.uk/ILdefinitionCILIP2018.pdf

CNN [@CNN] (2020). Spanish Prime Minister Pedro Sánchez said rankings by Johns Hopkins University showed Spain was fifth in the world in testing rates. But those international rankings appear not to exist [tuit]. Twitter. https://twitter.com/CNN/status/1259336128634720256

Editorial Nobbot (2020). Periodismo abierto y responsabilidad compartida en tiempos del coronavirus. Nobbot. https://www.nobbot.com/articulos/bulossobre-el-coronavirus-periodismo/

Elsevier Connect (2020). 'Fake news', bulos y contenidos en salud: una tendencia con muchos riesgos. Elsevier. https://tinyurl.com/7sarh2jm7

Encabo, I. (2020). La falta de una definición de fake-news permite a los Gobiernos acercarse a la censura. El Independiente. https://tinyurl.com/3nxhae26

European Commission (2018). Report: Flash Eurobarometer 464. Fake news and disinformation online. March, 13. https://doi.org/doi:10.2759/559993

Finley, W., McGowan, B. y Kluever, J. (2017). Fake news: An opportunity for real librarianship. ILA reporter, $X X X V(3)$. https://tinyurl.com/shd62tdu

Furlan, A. (2021). Guía para desmentir 24 bulos sobre la vacuna de COVID-19. The Conversation. https://tinyurl.com/4j8j7m7y 
García, G. J. (2019). Las fake news en la lógica de la posverdad. p. 12. https://tinyurl.com/uku72xdj

Garea, F. (2020). La Fiscalía considera que difundir bulos puede incurrir en una decena de delitos. El Confidencial. https://tinyurl.com/4e79c9yn

González, J. M. (2019). El doble salto mortal de Ana Pastor, juez y parte: ¿quién vigila a la vigilante de las fake news? El Español. https://tinyurl.com/62f85283

Gosálvez, P. (2018). Marihuana en el botafumeiro, ¿puede un chiste ser 'fake news'? El País. https://tinyurl.com/mz6fujxp

Gragnani, J. (2018). Guía básica para identificar noticias falsas (antes de mandarlas a tus grupos de WhatsApp). BBC. https://www.bbc.com/mundo/noticias-45561204

IFeel (2020). La psicología del bulo: así actúa nuestra mente ante las noticias falsas. Ethic. https://ethic.es/2020/05/la-psicologia-del-bulo/

International Federation of Libraries Association, IFLA. (2021). How to spot fake news. https://www.ifla.org/publications/node/11174

Larraz, I. (2020). Es falso que España sea el octavo país de la OCDE con más test por habitante. Newtral.es. https://tinyurl.com/96s8nx7a

Llorca, A. A. (2017). ¿Verdad o ficción? Esta guía para identificar noticias falsas te ayudará a saberlo. Nobbot. https://www.nobbot.com/redes/como-identificarnoticias-falsas/

Lorenzo, A. (2020). Ni causan hipoxia ni han muerto niños por usarlas en Alemania: los bulos sobre las mascarillas durante la pandemia de COVID-19. Newtral.es. https://tinyurl.com/579t9b4z

Maldito Bulo (2021). La COVID-19 y sus bulos: 1127 mentiras, alertas falsas y desinformaciones sobre el coronavirus. Maldita.es https://tinyurl.com/fr353yc

Maldito Dato (2020). Es falso que España sea el primer país que «tomó medidas de confinamiento en todo Occidente» como dice Pedro Sánchez. Maldita.es. https://tinyurl.com/th4ybajn

Maldonado, A. (2020). 'Fake news' versus realidad. The Huffington Post. https://tinyurl.com/ey6nhwsd

Masip, P., Aran-Ramspott, S., Ruiz-Caballero, C., Suau, J., Almenar, E. y PuertasGraell, D. (2020). Consumo informativo y cobertura mediática durante el confinamiento por el Covid-19: sobreinformación, sesgo ideológico y sensacionalismo. El profesional de la información, 29(3), e290312. https://doi.org/10.3145/epi.2020.may.12 
PREVENCIÓN DE LA DIFUSIÓN DE FAKE NEWS Y BULOS DURANTE LA PANDEMIA DE COVID-19 EN ESPAÑA. DE LA PENALIZACIÓN AL IMPULSO DE LA ALFABETIZACIÓN INFORMACIONAL

McLean, S. y Pérez Maestro, L. (2020, May). Spanish prime minister fails to prove existence of international coronavirus testing rankings he cited. CNN. https://tinyurl.com/94pe4uek

Mejías, M. y López, N. (2020, 7 de abril). Los bulos se extienden en la red sin fácil castigo en el Código Penal. Agencia EFE. https://tinyurl.com/swp4xds

Montesi, M. (2020). Las fake news sobre el COVID-19: ¿qué aprendemos de ellas? [Preprint] http://eprints.rclis.org/39894/

Moreno-Castro, C., Vengut-Climent, E, Cano-Orón, L. y Mendoza-Poudereux, I. (2021). Exploratory study of the hoaxes spread via WhatsApp in Spain to prevent and/or cure COVID-19. Gaceta Sanitaria. https://doi.org/10.1016/j.gaceta.2020.07.008

Newtral (2019). Ocho claves para detectar noticias falsas. Newtral. https://tinyurl.com/2t8af6ye

Organización Mundial de la Salud (2020). Novel coronavirus (2019-nCoV). Situation report - 13. https://tinyurl.com/3wp46ted

Ortega, A. (2020). Infodemia y mediademia. Real Instituto Elcano. https://blog.realinstitutoelcano.org/infodemia-y-mediademia/

Parra-Valero, P. y Oliveira, L. (2018). Fake news: una revisión sistemática de la literatura. (OBS*) Observatorio Journal, Special Issue, 54-78. https://doi.org/10.15847/obsOBS12520181374

Pérez-Dasilva, J. A., Meso-Ayerdi, K. y Mendiguren-Galdospín, T. (2020). Fake news y coronavirus: detección de los principales actores y tendencias a través del análisis de las conversaciones en Twitter. El profesional de la información, 29(3), e290308. https://doi.org/10.3145/epi.2020.may.08

Pérez Rodríguez, M. A. (2020). El Gobierno concedió a la 'verificadora de bulos' Maldita.es una subvención de 6.000 euros antes de las elecciones. Libertad Digital. https://tinyurl.com/c2zvjcw

Peña, G., Bermejo, E. y Zanni, S. (2021). Fact checking durante la COVID-19: análisis comparativo de la verificación de contenidos falsos en España e Italia. Revista de Comunicación, 20(1), 197-215. https://doi.org/10.26441/RC20.1-2021$\underline{\mathrm{A} 11}$

Plous, S. (1993). The Psychology of Judgment and Decision Making. New York: McGraw-Hill. ISBN: 9780070504776

Pool Moncloa / Villar, J. y del Monte, D. (2020). Rueda de prensa de los ministros de Interior, Fernando Grande-Marlaska, y de Justicia, Juan Carlos Campo. La Moncloa. https://tinyurl.com/tbwanxdf 
Radiotelevisión Española (2020, 21 de abril). Entrevista en TVE. Celaá justifica que la Guardia Civil desmienta bulos contra la ciencia y «contra la integridad de las instituciones». RTVE.es. https://tinyurl.com/rn8hn3zv

Salaverría, R., Buslón, N., López-Pan, F., León, B., López-Goñi, I. y Erviti, M. C. (2020). Desinformación en tiempos de pandemia: tipología de los bulos sobre la Covid-19. El profesional de la información, 29(3), e290315. https://doi.org/10.3145/epi.2020.may.15

Sánchez-Duarte, J. M. y Magallón, R. (2020). Infodemia y COVID-19. Evolución y viralización de informaciones falsas en España. Revista española de comunicación en salud, Suplemento 1, 31-41. http://dx.doi.org/10.20318/recs.2020.5417

Tandoc, E. C. Jr., Lim, Z. W. y Ling, R. (2018). Defining «Fake News». Digital Journalism, 6(2), 137-153. https://doi.org/10.1080/21670811.2017.1360143

Terradillos, A. (2020, 20 de abril). Guardia Civil insta a identificar fake news susceptibles de crear «desafección a instituciones del Gobierno». Cadena Ser. https://tinyurl.com/27e6ttaw

Trillo, M. (2020, 1 de mayo). Sin rastro de un estudio de la Universidad Johns Hopkins del que alardeó Pedro Sánchez. $A B C$. https://tinyurl.com/3vja2vj2

Urreiztieta, E. (2020, 11 de mayo). Dolores Delgado: «Vamos a investigarlo todo, las víctimas son una prioridad». El Mundo. https://tinyurl.com/3h6w37ew

Villa Gracia, A. D. y Cerdán Martínez, V. (2020). Bulos durante la pandemia del Covid-19 en España: un estudio a través de Google Trends. Revista Latina de Comunicación Social, 78, 169-182. https://www.doi.org/10.4185/RLCS-2020-1473

Vosoughi, S., Roy, D. y Aral, S. (2018). The spread of true and false news online. Science, 359 (6380), 1146-1151. https://doi.org/10.1126/science.aap9559

Wardle, C. (2017). Fake News. It's Complicated. First Draft. https://firstdraftnews.org/latest/fake-news-complicated/

\section{AUTOR}

\section{Juan Antonio Martínez Sánchez}

Doctorando en el programa de Ciencias Jurídicas y Sociales de la Universidad de Cádiz. Licenciado en Psicología por la Universidad de Sevilla, militar de carrera y Titulado Superior de la Administración (analista de información) en excedencia. Docente colaborador de diversos programas universitarios de postgrado, es autor de diversas publicaciones en Journals indexados. Su línea actual de investigación se centra en la psicología de las fakes y los sesgos cognitivos del análisis de información.

Orcid ID: https://orcid.org/0000-0002-7696-5023

Geogle Schoolar: https://scholar.google.es/citations?user=kzh0 mcAAAAJ\&hl=es

ResearchID: https://www.researchgate.net/profile/Juan-Martinez-Sanchez-2 